\title{
High Neutrophil-lymphocyte Ratio Is a Prognostic Marker for Mortality in Severe Covid-19 and Is Associated With Elevated Age and Kidney Failure
}

Heitor Santos ( $\sim$ heitoroliveirasantos@gmail.com )

Federal University of Uberlandia: Universidade Federal de Uberlandia https://orcid.org/0000-00034317-9365

Felipe Delpino

Federal University of Pelotas: Universidade Federal de Pelotas

Octavio Veloso

Federal University of Sergipe: Universidade Federal de Sergipe

Juliana Freire

Hospital São Lucas: Hospital Sao Lucas

Erlaine Gomes

Hospital São Lucas: Hospital Sao Lucas

Cristina Pereira

Federal University of Sergipe: Universidade Federal de Sergipe

\section{Research Article}

Keywords: COVID-19, intensive care unit, lymphocytes, neutrophils, NLR

Posted Date: December 14th, 2021

DOI: https://doi.org/10.21203/rs.3.rs-1154919/v1

License: (c) (i) This work is licensed under a Creative Commons Attribution 4.0 International License. Read Full License 


\section{Abstract}

Neutrophil and lymphocyte ratio (NLR) has emerged as a prognostic marker in intensive care. This study aimed to associate high NLR values with COVID-19-associated diseases and mortality among critically ill patients. A cross-sectional study encompassing 189 critically ill patients with COVID-19 was performed. Crude model and adjusted (1- age; 2- sex; 3- kidney failure, diabetes, obesity, hypertension, sex, and age) modes were used. Participants with NLR $\geq 10.6$ were older than those with NLR $<10.6(p<0.001)$. The number of deaths (37 vs. $18, p=0.001$ ) and patients with kidney failure (30 vs. $20, p=0.045$ ) were higher for NLR $\geq 10.6$ than NLR $<10.6$. NLR $\geq 10.6$ was associated with higher number of deaths for the crude model (OR: 3.10 [95\%Cl:1.60-6.01], $p=0.001$ ), age-adjusted (OR: 2.62 [95\%Cl:1.32-5.20], $p=0.006$ ) and sex-adjusted (OR: 2.97 [95\%Cl:1.52-5.78], $\mathrm{p}=0.031$ ), as well as in the fully-adjusted model (OR: 2.48 [95\%Cl:1.21-5.08], $p=0.013$ ), when compared to NLR $<10.6$. Older adults ( $\geq 60 \mathrm{y})$ had an OR of 2.61 (95\%Cl:1.26-5.39, $\mathrm{p}=0.010)$ for mortality compared to adults $(\leq 59 \mathrm{y})$, and the same value was found for the model adjusted for sex (OR: 2.61 [95\% Cl:1.26-5.42], $\mathrm{p}=0.010$ ). Kidney failure was associated with mortality for the crude model (OR: 2.58 [95\%Cl:1.30-5.11], $\mathrm{p}=0.007$ ), age-adjusted (OR: 2.09 [95\% Cl:1.024.27], $p=0.044$ ), and sex-adjusted (OR: 2.45 [95\% Cl:1.23-4.89], $p=0.011$ ). In conclusion, high NLR is a prognostic marker for mortality in severe COVID-19 and is associated with advanced age and kidney failure.

\section{Introduction}

Neutrophils and lymphocytes are cells of the immune system that are part of the pathophysiological process of many diseases, whose blood concentrations can be used to monitor hospitalized patients.[14] Since neutrophils produce several pro-inflammatory cytokines, high blood concentrations of neutrophils are a harbinger of greater stress oxidative mainly in most vulnerable patients,[5-8] including critically ill patients with Coronavirus Disease 2019 (COVID-19), by which excessive levels of reactive oxygen species (ROS) are responsible for lung tissue damage, thrombosis, and red blood cell dysfunction, thus entailing COVID-19 disease severity.[9] Regarding lymphocytes, the lower concentration, the higher stress oxidative, given that a plethora of anti-inflammatory cytokines (e.g., interleukin (IL)-4, IL-10, IL-13, and interferon-gamma) is derived from lymphocytes. $[10,11]$ More importantly, lymphopenia is widely recognized as a marker of poor survival outcomes and has been replicated in COVID-19 pandemic.[12]

In this light, neutrophil and lymphocyte ratio (NLR) has been evoked by massive research as a prognostic marker of diseases linked to intensive care.[12-15] Given that the critical illness in COVID-19 remains a current concern worldwide and that NLR merits further investigation as a prognostic marker in this regard due to the lack of cutoff values, we carried out a cross-sectional study in an attempt to expand the association between high NLR values and clinical characteristics and outcomes of critically ill patients with COVID-19, including COVID-19-associated diseases and mortality.

\section{Methods}




\subsection{Study design and patients}

A cross-sectional study was conducted in the Intensive Care Unit (ICU) specialized in the treatment of COVID-19 at Hospital São Lucas (HSL), Rede D'OR - São Luiz, Aracaju/Sergipe, Brazil. This research is affiliated with the Federal University of Sergipe and was approved by the local Research Ethics Committee ( $n^{\circ} 35128820.0 .0000 .5546$.). All volunteers who agreed to be evaluated signed a consent form.

Inclusion criteria were $\geq 18$ years, patients of both sexes, COVID-19 diagnosis, and available neutrophil and lymphocyte count. One-hundred (190) volunteers were enrolled, by which only one patient was excluded due to the lack of neutrophil and lymphocyte count. The low number of exclusion occurred mainly because the neutrophil and lymphocyte count are routinely markers ordered in the ICU. Clinical and demographic variables were acquired directly by physicians or medical students under supervision using medical records.

\subsection{Biochemical analyses}

Diagnosis of COVID-19 was detected by reverse-transcription PCR (RT-PCR), which was non-randomly collected without contact with patients from electronic medical records. After venous blood collection carried out by a phlebotomy specialist and ensuing centrifugation, the cytometric method based on laser

light scattering was used to obtain the leukogram values (normal range: $4,000-11,000 \mathrm{cell} / \mathrm{mm}^{3}$ ) from the samples, thus extracting the neutrophil and lymphocyte counts to divide them in this sequence to generate the NLR.

The variables collected for this article were: sociodemographic data (sex and age) and typical COVID-19associated diseases previous to COVID-19 diagnosis (hypertension, obesity, diabetes, and kidney failure).

\subsection{Statistical analyses}

ICU patients were categorized according to NLR cutoff (explained in the paragraph below). ICU discharge or death were registered as the main outcome. We categorized the patients into adults (up to 59 years old) or older adults (60 years and older). Sex was categorized as male or female, while obesity, diabetes, and kidney failure as "no" or "yes". Categorical variables were described by means of absolute frequency $(\mathrm{N})$ and percentage (\%). Continuous or discrete variables were defined with median and standard deviation (SD).

We estimated the best NLR cutoff point for ICU hospital discharge or death by calculating the sensitivity, specificity, and area under the Receiver Operating Characteristic (ROC) curve. The significance level was set at $5 \%$. The cutoff value was chosen based on the AUC value and a balance between specificity and sensitivity values. The next step was to dichotomize the NLR value according to the previous cutoff selected. Differences between groups were tested with Pearson's chi-squared test for categorical variables and analysis of variance (ANOVA) for continuous. 
We performed the analyses for four models: crude, adjusted for age or sex, and fully-adjusted model (kidney failure, diabetes, obesity, hypertension, sex, and age). Logistic regression was performed with a confidence interval of $95 \%$, and the results presented as Odds Ratio (OR). P-values $<0.05$ were considered as significant. We performed the analyses using Stata 15.1 (StataCorp, College Station, TX, USA).

\section{Results}

An NLR cutoff value $\geq 10.6$ was chosen employing area under the curve (AUC) equivalent to $0.6551 \pm$ 0.05 (95\% Cl:0.57-0.73), sensitivity of $67 \%$, and specificity of $60 \%$ (Figure 1 ). The sociodemographic and clinical characteristics divided by NLR cutoff values are shown in Table 1. Participants with NLR $\geq 10.6$ were older than those with NLR $<10.6$ (68.7 \pm 13.5 vs $60.2 \pm 17.6 ; p<0.001)$, but without differences for sex, prevalence of hypertension, obesity, and diabetes $(p>0.05)$. The number of deaths ( $37 \mathrm{vs.} 18, p=$ 0.001 ) and kidney failure ( $30 \mathrm{vs.} 20, p=0.045$ ) were higher for NLR $\geq 10.6$, whereas lymphocytes, neutrophils, and NLR were different between the groups ( $p<0.001$ for all).

Table 1

Socio-demographic characteristics and clinical characteristics of the patients according to the neutrophils-lymphocytes ratio.

\begin{tabular}{|c|c|c|c|}
\hline Variables & $\begin{array}{l}\text { NLR }<10.6 \\
(n=98)\end{array}$ & $\begin{array}{l}\text { NLR } \geq 10.6 \\
(n=91)\end{array}$ & p-value \\
\hline Age (years) & $60.2 \pm 17.6$ & $68.7 \pm 13.5$ & $<0.001$ \\
\hline \multicolumn{4}{|l|}{ Sex n (\%) } \\
\hline Male & $53(54.0)$ & $61(67.0)$ & \multirow[t]{2}{*}{0.069} \\
\hline Female & $45(46.0)$ & $30(33.0)$ & \\
\hline Hypertension n (\%) & $56(57.0)$ & $60(65.9)$ & 0.215 \\
\hline Obesity n (\%) & $33(33.7)$ & $28(30.8)$ & 0.670 \\
\hline Diabetes n (\%) & $41(41.8)$ & $30(33.3)$ & 0.208 \\
\hline Death $\mathrm{n}(\%)$ & $18(18.4)$ & $37(41.1)$ & 0.001 \\
\hline Lymphocytes $\left(\mathrm{mm}^{3}\right)$ & $1490.5 \pm 1825.4$ & $649.4 \pm 355.5$ & $<0.001$ \\
\hline Neutrophils $\left(\mathrm{mm}^{3}\right)$ & $7128.7 \pm 4026.0$ & $11216.0 \pm 5190.7$ & $<0.001$ \\
\hline NLR & $5.90 \pm 2.6$ & $20.9 \pm 12.5$ & $<0.001$ \\
\hline Kidney dysfunction n (\%) & $20(20.4)$ & $30(33.3)$ & 0.045 \\
\hline \multicolumn{4}{|c|}{ *Significant differences between NLR categories are in bolt. } \\
\hline $\begin{array}{l}\text { *Pearson's chi-squared te } \\
\text { test for continuous. }\end{array}$ & to test differenc & en categorical vari & ANOVA \\
\hline
\end{tabular}


Table 2 shows the association between sociodemographic and clinical characteristics for registered deaths. Comparing to adults, older adults had an OR of $2.61(95 \% \mathrm{Cl}: 1.26-5.39, \mathrm{p}=0.010)$ for mortality. The same value was found in the model adjusted for sex (OR: 2.61 [95\% Cl:1.26-5.42], $\mathrm{p}=0.010$ ). NLR $\geq 10.6$ was associated with higher number of deaths for crude model (OR: 3.10 [95\%Cl:1.60-6.01], $p=$ 0.001), adjusted for age (OR: 2.62 [95\%Cl:1.32-5.20], $\mathrm{p}=0.006$ ) and sex (OR: 2.97 [95\%Cl:1.52-5.78], $\mathrm{p}=$ 0.031 ), as well as in the fully-adjusted model (OR: 2.48 [95\% Cl:1.21-5.08], $\mathrm{p}=0.013$ ), when compared to NLR < 10.6. Furthermore, kidney failure was associated with mortality for crude model (OR: 2.58 [95\% Cl:1.30-5.11], $p=0.007)$, as well as models adjusted for age (OR: 2.09 [95\% Cl:1.02-4.27], $p=0.044$ ) and for sex (OR: 2.45 [95\%Cl:1.23-4.89], p = 0.011). Sex, hypertension, obesity, and diabetes were not associated with higher NLR values or mortality in any analysis performed. 
Table 2

Association between socio-demographic characteristics and clinical characteristics of the patients with ICU mortality $(n=55)$.

\begin{tabular}{|c|c|c|c|c|c|c|c|c|}
\hline \multirow[t]{2}{*}{ Variables } & $\begin{array}{l}\text { OR } \\
\text { (CI95\%) }\end{array}$ & $\begin{array}{l}\mathrm{p}- \\
\text { value }\end{array}$ & $\begin{array}{l}\text { OR } \\
\text { (Cl95\%) }\end{array}$ & $\begin{array}{l}\mathrm{p}- \\
\text { value }\end{array}$ & $\begin{array}{l}\text { OR } \\
\text { (Cl95\%) }\end{array}$ & $\begin{array}{l}\mathrm{p}- \\
\text { value }\end{array}$ & $\begin{array}{l}\text { OR } \\
\text { (Cl95\%) }\end{array}$ & $\begin{array}{l}\mathrm{p} \text { - } \\
\text { value }\end{array}$ \\
\hline & \multicolumn{2}{|l|}{ Crude } & \multicolumn{2}{|l|}{$\begin{array}{l}\text { Adjusted } \\
\text { for age }\end{array}$} & \multicolumn{2}{|l|}{$\begin{array}{l}\text { Adjusted } \\
\text { for sex }\end{array}$} & \multicolumn{2}{|l|}{$\begin{array}{l}\text { Fully- } \\
\text { adjusted } \\
\text { model }\end{array}$} \\
\hline \multicolumn{9}{|l|}{ Age } \\
\hline Adults & Ref & & - & & ref & & ref & \\
\hline \multirow[t]{2}{*}{ Older adults } & 2.61 & 0.010 & - & - & 2.61 & 0.010 & 1.55 & 0.323 \\
\hline & $\begin{array}{l}(1.26- \\
5.39)\end{array}$ & & & & $\begin{array}{l}(1.26- \\
5.42)\end{array}$ & & $\begin{array}{l}(0.65- \\
3.73)\end{array}$ & \\
\hline \multicolumn{9}{|l|}{ Sex } \\
\hline Female & Ref & & Ref & & - & & ref & \\
\hline \multirow[t]{2}{*}{ Male } & 1.73 & 0.108 & 1.73 & 0.112 & - & - & 1.41 & 0.343 \\
\hline & $\begin{array}{l}(0.89- \\
3.37)\end{array}$ & & $\begin{array}{l}(0.88- \\
3.42)\end{array}$ & & & & $\begin{array}{l}(0.69- \\
2.89)\end{array}$ & \\
\hline \multicolumn{9}{|l|}{ Hypertension } \\
\hline No & Ref & & Ref & & ref & & ref & \\
\hline \multirow[t]{2}{*}{ Yes } & 1.63 & 0.154 & 1.12 & 0.764 & 1.66 & 0.140 & 1.08 & 0.849 \\
\hline & $\begin{array}{l}(0.83- \\
3.17)\end{array}$ & & $\begin{array}{l}(0.53- \\
2.36)\end{array}$ & & $\begin{array}{l}(0.85- \\
3.25)\end{array}$ & & $\begin{array}{l}(0.49- \\
2.38)\end{array}$ & \\
\hline \multicolumn{9}{|l|}{ Obesity } \\
\hline No & Ref & & Ref & & ref & & ref & \\
\hline \multirow[t]{2}{*}{ Yes } & 0.94 & 0.849 & 1.08 & 0.832 & 0.92 & 0.820 & 1.07 & 0.858 \\
\hline & $\begin{array}{l}(0.48- \\
1.84)\end{array}$ & & $\begin{array}{l}(0.54- \\
2.17)\end{array}$ & & $\begin{array}{l}(0.47- \\
1.83)\end{array}$ & & $\begin{array}{l}(0.52- \\
2.21)\end{array}$ & \\
\hline \multicolumn{9}{|l|}{ Diabetes } \\
\hline No & Ref & & Ref & & ref & & ref & \\
\hline
\end{tabular}

*Significant differences between NLR cutoff are in bolt.

*OR (Odds Ratio).

*Fully-adjusted model was adjusted for kidney dysfunction, diabetes, obesity, hypertension, sex, and age. 


\begin{tabular}{|c|c|c|c|c|c|c|c|c|}
\hline \multirow[t]{2}{*}{ Variables } & $\begin{array}{l}\text { OR } \\
\text { (Cl95\%) }\end{array}$ & $\begin{array}{l}\mathrm{p}- \\
\text { value }\end{array}$ & $\begin{array}{l}\text { OR } \\
\text { (Cl95\%) }\end{array}$ & $\begin{array}{l}\mathrm{p}- \\
\text { value }\end{array}$ & $\begin{array}{l}\text { OR } \\
\text { (Cl95\%) }\end{array}$ & $\begin{array}{l}\mathrm{p}- \\
\text { value }\end{array}$ & $\begin{array}{l}\text { OR } \\
\text { (Cl95\%) }\end{array}$ & $\begin{array}{l}\text { p- } \\
\text { value }\end{array}$ \\
\hline & \multicolumn{2}{|l|}{ Crude } & \multicolumn{2}{|l|}{$\begin{array}{l}\text { Adjusted } \\
\text { for age }\end{array}$} & \multicolumn{2}{|l|}{$\begin{array}{l}\text { Adjusted } \\
\text { for sex }\end{array}$} & \multicolumn{2}{|l|}{$\begin{array}{l}\text { Fully- } \\
\text { adjusted } \\
\text { model }\end{array}$} \\
\hline \multirow[t]{2}{*}{ Yes } & 1.27 & 0.462 & 1.01 & 0.971 & 1.20 & 0.583 & 1.16 & 0.695 \\
\hline & $\begin{array}{l}(0.67- \\
2.42)\end{array}$ & & $\begin{array}{l}(0.52- \\
1.98)\end{array}$ & & $\begin{array}{l}(0.63- \\
2.30)\end{array}$ & & $\begin{array}{l}(0.56- \\
2.39)\end{array}$ & \\
\hline \multicolumn{9}{|c|}{$\begin{array}{l}\text { Neutrophils- } \\
\text { lymphocytes } \\
\text { ratio (NLR) }\end{array}$} \\
\hline$<10.6$ & Ref & & Ref & & ref & & ref & \\
\hline \multirow[t]{2}{*}{$\geq 10.6$} & 3.10 & 0.001 & 2.62 & 0.006 & 2.97 & 0.001 & 2.48 & 0.013 \\
\hline & $\begin{array}{l}(1.60- \\
6.01)\end{array}$ & & $\begin{array}{l}(1.32- \\
5.20)\end{array}$ & & $\begin{array}{l}(1.52- \\
5.78)\end{array}$ & & $\begin{array}{l}(1.21- \\
5.08)\end{array}$ & \\
\hline \multicolumn{9}{|c|}{$\begin{array}{l}\text { Kidney } \\
\text { dysfunction }\end{array}$} \\
\hline No & Ref & & Ref & & ref & & ref & \\
\hline \multirow[t]{2}{*}{ Yes } & 2.58 & 0.007 & 2.09 & 0.044 & 2.45 & 0.011 & 1.88 & 0.099 \\
\hline & $\begin{array}{l}(1.30- \\
5.11)\end{array}$ & & $\begin{array}{l}(1.02- \\
4.27)\end{array}$ & & $\begin{array}{l}(1.23- \\
4.89)\end{array}$ & & $\begin{array}{l}(0.89- \\
3.97)\end{array}$ & \\
\hline \multicolumn{9}{|c|}{ *Significant differences between NLR cutoff are in bolt. } \\
\hline \multicolumn{9}{|c|}{ *OR (Odds Ratio). } \\
\hline $\begin{array}{l}\text { ^Fully-adji } \\
\text { age. }\end{array}$ & I was ad & Isted for & kidney dysf & nction, & abetes, obc & ity, hyp & ension, s & and \\
\hline
\end{tabular}

\section{Discussion}

In this study, higher NLR was considered a prognostic marker of COVID-19 mortality in critically ill patients, as observed in crude and adjusted models. More specifically, patients with higher NLR (NLR 210.6) had a 3.1 and 2.5 times greater likelihood of having COVID-19 mortality for the crude (OR: 3.10, CI95\% 1.60-6.01) and the fully-adjusted model (OR: 2.48, CI95\% 1.21-5.08) compared to those with lower NLR (NLR <10.6). However, it is noteworthy to mention that even the lower NLR mean $(5.90 \pm 2.6$ for NLR $<10.6$ ) in our study is an alarming rate if extrapolated to other populations, such as inpatients, given the close link of these values with chronic low-grade systemic inflammation (e.g., diabetes, obesity, and cardiovascular and renal diseases).[16-19] The higher NLR mean (20.9 \pm 12.5 for NLR $\geq 10.6)$ found herein seemingly is related to an exceedingly high inflammatory response to COVID-19-related critical illness triggered by cytokine storm.[20-22] 
Higher NLR was associated with advanced age (crude analysis and sex-adjusted) and kidney failure (crude analysis and adjusted for sex and age). Regarding advanced age, although the number of circulating neutrophils is generally similar to young controls in the absence of infection,[23] increased NLR is conceivable in virtue of immunosenescence related to reduced production and change in the composition of lymphocytes, mainly CD4+ and CD8+ T cells and B lymphocytes.[24] Concerning the relationship between higher NLR and kidney failure, it can be related to advanced immunoinflammatory activity in the nephrons accompanied by impaired glomerular filtration barrier or impaired tubular function, whose raised stress oxidative is present in both acute kidney injury and in chronic kidney disease.[25, 26]

Recognizably, low lymphocyte count is a predictor marker of mortality in intensive care.[27-29] That said, higher NLR due to low lymphocyte count would be expected to be in COVID-19 mortality, and we confirmed this clinical link by comparing patients with NLR $>10.6 \mathrm{vs.} \leq 10.6$. Similarly, Ullah et al. considered NLR $>11$ as a predictor of COVID-19 mortality when compared to $<10$, but did not perform specific analyses to find an ideal cutoff point.[30] Noteworthy, the higher NLR mean (20.9 \pm 12.5 for patients with NLR $\geq 10.6)$ of our study was similar to the mean $(20.7 \pm 24.1)$ observed by Yang et al. for critically ill patients with COVID-19, despite a low sample size $(n=24)$.[31] In contrast, some studies show low mean or median NLR values $(3.7(2.0,6.7) n=28$; [32] $4.24(3.00-10.87) n=16$; [33] $6.29 \pm 3.72, n=$ 16 [34]) for patients with severe COVID-19 if compared to our findings, but their sample size is insufficient to draw a reliable cutoff point.

A recent meta-analysis on COVID-19 patients showed that elevated NLR levels on admission were associated with a risk $174 \%$ higher of having mortality (RR: $2.74,95 \% \mathrm{Cl} 0.98-7.66$ ).[35] The authors emphasized the importance to establish an optimal cutoff value for NLR, and our study help in expanding this background to clinical practice.[35] We considered the NLR cutoff of $>10.6$ in order to maintain a balanced sensitivity $(67 \%)$ and specificity $(60 \%)$, avoiding very high levels or moderate levels that are ubiquitously associated with myriad diseases, mainly cardiovascular diseases, and related metabolic problems.

To the best of our knowledge, this is the first study that examined the association between NLR and COVID-19-associated diseases and mortality in South America, bringing a representative sample of a continental country like Brazil. The majority of research that analyzed this association was conducted in Chine,[31-34, 36-40] with a couple of studies in the US[30, 41] and Europe (e.g. Turkey and Italy[42-45]), in which high NLR was deemed as a prognostic marker of COVID-19-related mortality and overall severity.

Ultimately, it is should be highlighted the pros and cons of using NLR as a surrogate inflammatory marker in the clinical setting. Taking into account the benefits, NLR is a cheap parameter as it is obtained by two components of the blood cell count (neutrophils and lymphocytes), which is perhaps the most ordered laboratory test worldwide to monitor basic and advanced clinical conditions (e.g., anemias and cancers). In contrast, attention to NLR per se as a marker of inflammation pathophysiologically lacks meticulousness, given the constellation of pro-inflammatory cytokines that are part of COVID-19 disease. 
Given that cytokines are not often analyzed in the real-world scenario due to the bereft of laboratory tools (reagents, kits, and machines) for the overall population and cutoff values to depict clinical recommendation, NLR deserves consideration at least to guide practitioners.

In conclusion, high NLR values are a prognostic marker for mortality in critically ill patients with COVID19. In addition, higher NLR values are associated with advanced age and kidney failure in this population. Thus, further attention to NLR is imperative in clinical practice as a cheap and useful tool to monitor patients with COVID-19 in intensive care.

\section{Declarations}

Ethics Approval and consent to participate. This research was ratified by the Federal University of Sergipe and was approved by the local Research Ethics Committee ( $n^{\circ} 35128820.0 .0000 .5546$.). Data were collected from the medical record system. There was no intervention.

Consent for publication. All authors consent to publication.

Availability of data and materials. Biochemical data were collected in the medical record of the São Lucas Hospital.

Competing interests. The authors declare no competing interests.

Funding. None.

Authors' contributions. HOS - Conceptualization, writing of original draft, review of manuscript. FMD Statistical analyses. OMV - data collection. JMRF - data collection. ESNG - data collection. CGMP project administration, data collection, and supervision. All authors critically revised the article and finally approved the version to be published.

Acknowledgments. We are thankful for the São Lucas Hospital. This work did not receive any specific grant from funding agencies in the public, commercial, or not-for-profit sectors. HOS has been supported by Coordenação de Aperfeiçoamento de Pessoal de Nível Superior-Brazil (CAPES).

\section{References}

1. Forget, P., C. Khalifa, J. P. Defour, D. Latinne, M. C. Van Pel, and M. De Kock. 2017. What is the normal value of the neutrophil-to-lymphocyte ratio? BMC research notes 10 (1): 12.

2. Karabinos, I., S. Koulouris, A. Kranidis, S. Pastromas, N. Exadaktylos, and A. Kalofoutis. 2009. Neutrophil count on admission predicts major in-hospital events in patients with a non-ST-segment elevation acute coronary syndrome. Clinical cardiology 32 (10): 561-568.

3. Honda, T., T. Uehara, G. Matsumoto, S. Arai, and M. Sugano. 2016. Neutrophil left shift and white blood cell count as markers of bacterial infection. Clinica chimica acta; international journal of 
clinical chemistry 457: 46-53.

4. Pereira, C. G. M., E. R. S. Santana, J. E. R. Ramos, H. da Silva, M. A. P. Nunes, S. C. Forbes, and H. O. Santos. 2021. Low Serum Zinc Levels and Associated Risk Factors in Hospitalized Patients Receiving Oral or Enteral Nutrition: A Case-Control Study. Clinical therapeutics 43 (2): e39-e55.

5. Vitte, J., B. F. Michel, P. Bongrand, and J. L. Gastaut. 2004. Oxidative stress level in circulating neutrophils is linked to neurodegenerative diseases. Journal of clinical immunology 24 (6): 683-692.

6. Maor, I., T. Rainis, A. Lanir, and A. Lavy. 2008. Oxidative stress, inflammation and neutrophil superoxide release in patients with Crohn's disease: distinction between active and non-active disease. Digestive diseases and sciences 53 (8): 2208-2214.

7. Johnson, J., R. M. Jaggers, G. Sreejit, A. Dahdah, A. J. Murphy, N. M. J. Hanssen, and P. Nagareddy: Oxidative stress in neutrophils: Implications for diabetic cardiovascular complications. Antioxidants \& redox signaling. 2021.

8. Santos, H. O., and L. F. Izidoro. 2018. Neutrophil-Lymphocyte Ratio in Cardiovascular Disease Risk Assessment. Int J Cardiovasc Sci 31 (5): 532-537.

9. Laforge, M., C. Elbim, C. Frere, M. Hemadi, C. Massaad, P. Nuss, J. J. Benoliel, and C. Becker. 2020. Tissue damage from neutrophil-induced oxidative stress in COVID-19. Nature reviews Immunology 20 (9): 515-516.

10. Chen, L., H. Deng, H. Cui, J. Fang, Z. Zuo, J. Deng, Y. Li, X. Wang, and L. Zhao. 2018. Inflammatory responses and inflammation-associated diseases in organs. Oncotarget 9 (6): 7204-7218.

11. Foster, M., and S. Samman. 2012. Zinc and regulation of inflammatory cytokines: implications for cardiometabolic disease. Nutrients 4 (7): 676-694.

12. Montiel-Cervantes, L. A., G. Medina, M. Pilar Cruz-Dominguez, S. M. Perez-Tapia, M. C. JimenezMartinez, H. I. Arrieta-Oliva, G. Carballo-Uicab, L. Lopez-Pelcastre, and R. Camacho-Sandoval. 2021. Poor Survival in COVID-19 Associated with Lymphopenia and Higher Neutrophile-Lymphocyte Ratio. The Israel Medical Association journal: IMAJ 23 (3): 153-159.

13. Salciccioli, J. D., D. C. Marshall, M. A. Pimentel, M. D. Santos, T. Pollard, L. A. Celi, and J. Shalhoub. 2015. The association between the neutrophil-to-lymphocyte ratio and mortality in critical illness: an observational cohort study. Critical care 19: 13.

14. Akilli, N. B., M. Yortanli, H. Mutlu, Y. K. Gunaydin, R. Koylu, H. S. Akca, E. Akinci, Z. D. Dundar, and B. Cander. 2014. Prognostic importance of neutrophil-lymphocyte ratio in critically ill patients: shortand long-term outcomes. The American journal of emergency medicine 32 (12): 1476-1480.

15. Liu, J., Y. Liu, P. Xiang, L. Pu, H. Xiong, C. Li, M. Zhang, J. Tan, Y. Xu, and R. Song, et al. 2020. Neutrophil-to-lymphocyte ratio predicts critical illness patients with 2019 coronavirus disease in the early stage. Journal of translational medicine 18 (1): 206.

16. Sari, I., M. Sunbul, C. Mammadov, E. Durmus, M. Bozbay, T. Kivrak, and F. Gerin. 2015. Relation of neutrophil-to-lymphocyte and platelet-to-lymphocyte ratio with coronary artery disease severity in patients undergoing coronary angiography. Kardiologia polska 73 (12): 1310-1316. 
17. Guo, X., S. Zhang, Q. Zhang, L. Liu, H. Wu, H. Du, H. Shi, C. Wang, Y. Xia, and X. Liu, et al. 2015. Neutrophil:lymphocyte ratio is positively related to type 2 diabetes in a large-scale adult population: a Tianjin Chronic Low-Grade Systemic Inflammation and Health cohort study. European journal of endocrinology 173 (2): 217-225.

18. Turkmen, K., I. Guney, F. H. Yerlikaya, and H. Z. Tonbul. 2012. The relationship between neutrophil-tolymphocyte ratio and inflammation in end-stage renal disease patients. Renal failure 34 (2): 155159.

19. Bozkus, F., N. Dikmen, A. Samur, N. Bilal, N. Atilla, and H. Arpag. 2018. Does the neutrophil-tolymphocyte ratio have any importance between subjects with obstructive sleep apnea syndrome with obesity and without obesity? Tuberkuloz ve toraks 66 (1): 8-15.

20. Soy, M., G. Keser, P. Atagunduz, F. Tabak, I. Atagunduz, and S. Kayhan. 2020. Cytokine storm in COVID-19: pathogenesis and overview of anti-inflammatory agents used in treatment. Clinical rheumatology 39 (7): 2085-2094.

21. Santos, H. O.: Therapeutic supplementation with zinc in the management of COVID-19-related diarrhea and ageusia/dysgeusia: mechanisms and clues for a personalized dosage regimen. Nutrition reviews 2021.

22. Santos, H. O., G. M. Tinsley, G. A. R. da Silva, and A. A. Bueno: Pharmaconutrition in the Clinical Management of COVID-19: A Lack of Evidence-Based Research But Clues to Personalized Prescription. Journal of personalized medicine 2020, 10(4).

23. Schroder, A. K., and L. Rink. 2003. Neutrophil immunity of the elderly. Mechanisms of ageing and development 124 (4): 419-425.

24. Navarro-Martinez, R., and O. Cauli: Lymphocytes as a Biomarker of Frailty Syndrome: A Scoping Review. Diseases 2021, 9(3).

25. Binnetoglu, E., E. Sengul, G. Halhalli, S. Dindar, and H. Sen. 2014. Is neutrophil lymphocyte ratio an indicator for proteinuria in chronic kidney disease? Journal of clinical laboratory analysis 28 (6): 487-492.

26. Kinsey, G. R., L. Li, and M. D. Okusa. 2008. Inflammation in acute kidney injury. Nephron Experimental nephrology 109 (4): e102-e107.

27. Izaks, G. J., E. J. Remarque, S. V. Becker, and R. G. Westendorp. 2003. Lymphocyte count and mortality risk in older persons. The Leiden 85-Plus Study. Journal of the American Geriatrics Society 51 (10): 1461-1465.

28. Kuwae, N., J. D. Kopple, and K. Kalantar-Zadeh. 2005. A low lymphocyte percentage is a predictor of mortality and hospitalization in hemodialysis patients. Clinical nephrology 63 (1): 22-34.

29. Vulliamy, P. E., Z. B. Perkins, K. Brohi, and J. Manson. 2016. Persistent lymphopenia is an independent predictor of mortality in critically ill emergency general surgical patients. European journal of trauma and emergency surgery: official publication of the European Trauma Society 42 (6): 755-760. 
30. Ullah, W., B. Basyal, S. Tariq, T. Almas, R. Saeed, S. Roomi, S. Haq, J. Madara, M. Boigon, and D. C. Haas, et al. 2020. Lymphocyte-to-C-Reactive Protein Ratio: A Novel Predictor of Adverse Outcomes in COVID-19. Journal of clinical medicine research 12 (7): 415-422.

31. Yang, A. P., J. P. Liu, W. Q. Tao, and H. M. Li. 2020. The diagnostic and predictive role of NLR, d-NLR and PLR in COVID-19 patients. International immunopharmacology 84: 106504.

32. Gong, J., J. Ou, X. Qiu, Y. Jie, Y. Chen, L. Yuan, J. Cao, M. Tan, W. Xu, and F. Zheng, et al. 2020. A Tool for Early Prediction of Severe Coronavirus Disease 2019 (COVID-19): A Multicenter Study Using the Risk Nomogram in Wuhan and Guangdong, China. Clinical infectious diseases: an official publication of the Infectious Diseases Society of America 71 (15): 833-840.

33. Zhu, Z., T. Cai, L. Fan, K. Lou, X. Hua, Z. Huang, and G. Gao. 2020. Clinical value of immuneinflammatory parameters to assess the severity of coronavirus disease 2019. International journal of infectious diseases: IJID : official publication of the International Society for Infectious Diseases 95: 332-339.

34. Fu, J., J. Kong, W. Wang, M. Wu, L. Yao, Z. Wang, J. Jin, D. Wu, and X. Yu. 2020. The clinical implication of dynamic neutrophil to lymphocyte ratio and D-dimer in COVID-19: A retrospective study in Suzhou China. Thrombosis research 192: 3-8.

35. Simadibrata, D. M., J. Calvin, A. D. Wijaya, and N. A. A. Ibrahim: Neutrophil-to-lymphocyte ratio on admission to predict the severity and mortality of COVID-19 patients: A meta-analysis. The American journal of emergency medicine. 2021. 42:60-69.

36. Yan, X., F. Li, X. Wang, J. Yan, F. Zhu, S. Tang, Y. Deng, H. Wang, R. Chen, and Z. Yu, et al. 2020. Neutrophil to lymphocyte ratio as prognostic and predictive factor in patients with coronavirus disease 2019: A retrospective cross-sectional study. Journal of medical virology 92 (11): 2573-2581.

37. Chen, R., L. Sang, M. Jiang, Z. Yang, N. Jia, W. Fu, J. Xie, W. Guan, W. Liang, and Z. Ni, et al. 2020. Longitudinal hematologic and immunologic variations associated with the progression of COVID-19 patients in China. The Journal of allergy and clinical immunology 146 (1): 89-100.

38. Ding, X., Y. Yu, B. Lu, J. Huo, M. Chen, Y. Kang, J. Lou, and Z. Liu. 2020. Dynamic profile and clinical implications of hematological parameters in hospitalized patients with coronavirus disease 2019. Clinical chemistry and laboratory medicine 58 (8): 1365-1371.

39. Liu, F., Q. Zhang, C. Huang, C. Shi, L. Wang, N. Shi, C. Fang, F. Shan, X. Mei, and J. Shi, et al. 2020. CT quantification of pneumonia lesions in early days predicts progression to severe illness in a cohort of COVID-19 patients. Theranostics 10 (12): 5613-5622.

40. Sun, S., X. Cai, H. Wang, G. He, Y. Lin, B. Lu, C. Chen, Y. Pan, and X. Hu. 2020. Abnormalities of peripheral blood system in patients with COVID-19 in Wenzhou, China. Clinica chimica acta; international journal of clinical chemistry 507: 174-180.

41. Tatum, D., S. Taghavi, A. Houghton, J. Stover, E. Toraih, and J. Duchesne. 2020. Neutrophil-toLymphocyte Ratio and Outcomes in Louisiana COVID-19 Patients. Shock (Augusta, Ga.) 54 (5): 652658. 
42. Ciccullo, A., A. Borghetti, L. Zileri Dal Verme, A. Tosoni, F. Lombardi, M. Garcovich, F. Biscetti, M. Montalto, R. Cauda, and S. Di Giambenedetto, et al. 2020. Neutrophil-to-lymphocyte ratio and clinical outcome in COVID-19: a report from the Italian front line. International journal of antimicrobial agents 56 (2): 106017.

43. Gelzo, M., S. Cacciapuoti, B. Pinchera, A. De Rosa, G. Cernera, F. Scialo, M. Mormile, G. Fabbrocini, R. Parrella, and I. Gentile, et al. 2021. Prognostic Role of Neutrophil to Lymphocyte Ratio in COVID-19 Patients: Still Valid in Patients That Had Started Therapy? Frontiers in public health 9: 664108.

44. Ok, F., O. Erdogan, E. Durmus, S. Carkci, and A. Canik. 2021. Predictive values of blood urea nitrogen/creatinine ratio and other routine blood parameters on disease severity and survival of COVID-19 patients. Journal of medical virology 93 (2): 786-793.

45. Guner, R., I. Hasanoglu, B. Kayaaslan, A. Aypak, A. Kaya Kalem, F. Eser, B. Ozdemir, E. M. Saricaoglu, M. Ayhan, and Y. Aybar Bilir, et al. 2020. COVID-19 experience of the major pandemic response center in the capital: results of the pandemic's first month in Turkey. Turkish journal of medical sciences 50 (8): 1801-1809.

\section{Figures}




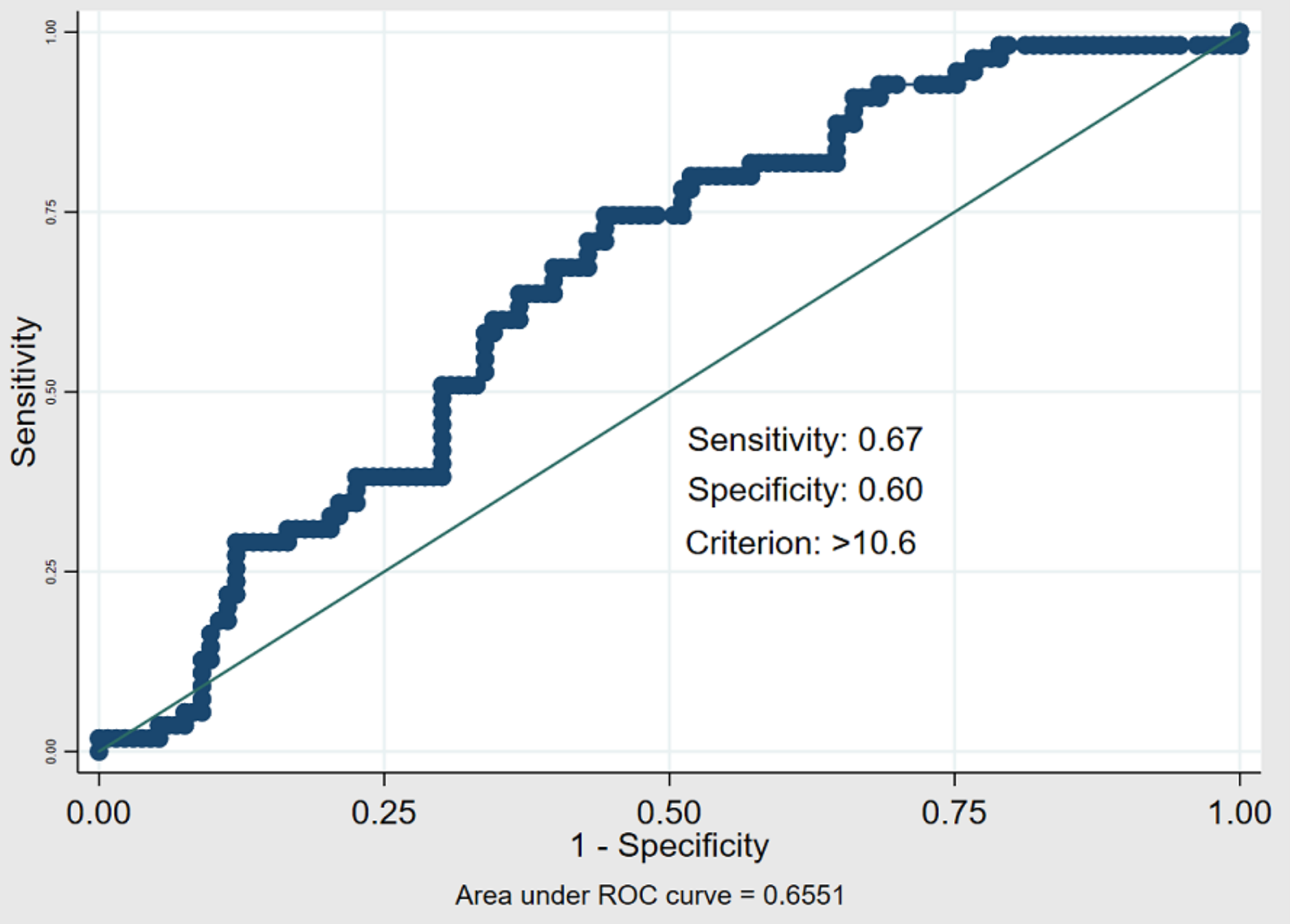

Figure 1

Receive Operating Characteristic (ROC) curve analysis for neutrophil-lymphocyte rate (NLR) cutoff to discriminate ICU outcome risk in COVID-19 patients 